\title{
Glial-neuronal ensembles: partners in drug addiction-associated synaptic plasticity
}

\author{
Jean Lud Cadet ${ }^{1 *}$ and Veronica Bisagno ${ }^{2}$ \\ ${ }^{1}$ Molecular Neuropsychiatry Research Branch, Intramural Research Program, National Institute on Drug Abuse-NIH, Baltimore, MD, USA \\ 2 Instituto de Investigaciones Farmacológicas (ININFA-UBA-CONICET), Buenos Aires, Argentina \\ *Correspondence: jcadet@intra.nida.nih.gov
}

Edited by:

M. Foster Olive, Arizona State University, USA

Reviewed by:

Olivier George, The Scripps Research Institute, USA

Keywords: synaptic plasticity, drug abuse, microglia, astroglia, oligodendroglia, inflammation

\section{INTRODUCTION}

Drug addiction is manifested by a compulsive drive to take licit or illicit substances despite repeated severe adverse consequences (Volkow et al., 2012). Addiction is also accompanied by a vicious cycle of binges, abstinence, and relapses. Almost all drugs of abuse trigger euphoric feelings consequent to a rapid increase of dopamine levels in the mesolimbic system. Even after long periods of abstinence, addicts remain vulnerable to drug craving and/or relapses that can be triggered by stimuli previously associated with drugs (Koob and Volkow, 2010). These features of addiction suggest that drugs might cause a form of persistent neuroplasticity that is acutely responsive to environmental stimuli, with consequent compulsive drug-seeking and taking behaviors.

Neural functions require the coordinated interactions of multiple neuronal cell types and a diverse population of glial cells. The three major glial cell types in the brain, astrocytes, oligodendrocytes, and microglia, communicate with each other and with neurons by using neurotransmitters, other small molecules, and gap junctions (Araque et al., 2014). Oligodendrocytes increase the speed of electrical transmission through nerve axons by forming the axonal myelin sheath and clustering ion channels at nodes of Ranvier (Nave, 2010). Microglia prune synapses in part by monitoring synaptic transmission (Schafer et al., 2013; Wake et al., 2013). Astrocytes can regulate synaptic transmission between neurons by modifying the concentration of extracellular potassium, controlling local blood flow, by releasing and/or taking up neurotransmitters or neuromodulators, by delivering nutrients to neurons, and by altering the geometry and volume of the brain extracellular space (Araque et al., 2014).

This brief summary of glial functions suggests that these cells might play important roles in the long-term manifestations of substance use disorders, both in terms of addiction to these agents and their longterm neuropsychiatric consequences. In what follows, we discuss some recent findings that support the thesis that glial cells are part and parcel of the plastic mechanisms that are induced by drugs of abuse.

\section{BRAIN INFLAMMATION TRIGGERED BY DRUGS OF ABUSE}

Gliosis and inflammatory responses are significant pathological features of substance use disorders (Cadet et al., 2014a). Inflammation is a natural response to damage and/or infection that are mediated by pro-inflammatory cytokines including interleukin 1 beta (IL-1 $\beta$ ), interleukin 6 (IL-6), and tumor necrosis factor alpha (TNF $\alpha)$ (Glass et al., 2010). In the brain, microglial cells are the main orchestrators of these neuroinflammatory responses (Jeong et al., 2013). However, other cells including astrocytes, endothelial cells, perivascular and meningeal macrophages, and even neurons, can also produce proinflammatory mediators (Van Wagoner et al., 1999; Jeong et al., 2013). These factors appear to mediate some detrimental effects of inflammation on neurogenesis (Sierra et al., 2014).

Brain inflammation is also associated with an increased production of reactive oxygen species (ROS) and nitric oxide (NO), followed by the propagation of free radicals that damage cells (Cadet and Brannock, 1998; Krasnova and Cadet, 2009). Indeed, various psychostimulants, including amphetamine and methamphetamine, can produce ROS in dopaminergic nerve terminal regions (Krasnova and Cadet, 2009; Shiba et al., 2011). Acute or repeated cocaine administration also generates ROS in dopaminergic rat brain structures (Dietrich et al., 2005). MDMA also produces reactive nitrogen species in the rat that contribute to its neurotoxicity (O'Shea et al., 2014).

\section{DRUGS ABUSE-INDUCED ALTERATIONS IN GLIAL CELLS \\ Astroglia}

Astrocytes play diverse roles in the regulation of synaptic transmission. They clear synaptic transmitters from the cleft through the activity of transporters and can recycle glutamate through a glutamine intermediate to the synaptic terminal (Haydon et al., 2009). Astrocytes can also release glutamate (D'Ascenzo et al., 2007; Jourdain et al., 2007), the NMDA receptor co-agonist D-serine (Mothet et al., 2005), and ATP (Cotrina et al., 2000). Hydrolysis of ATP to adenosine is responsible for an adenosine 1 (A1) receptor-mediated presynaptic inhibition of excitatory synaptic transmission (Volterra and Meldolesi, 2005).

GFAP-positive glial cells in the mPFC contain cystine/glutamate antiporters (Pow, 2001) that maintain extracellular non-synaptic glutamate levels and provide functional support to neurons by 
regulating extracellular potassium and the reuptake of glutamate at synapses (Wigley et al., 2007). Interestingly, non-synaptic glutamate derived from cystine/glutamate antiporters has been reported to modulate synaptic glutamate release and to regulate cocaine-induced drug seeking in rats (Moran et al., 2005). Moreover, down-regulation of the cystine/glutamate exchanger was reported to account for chronic cocaine-induced reduction in basal glutamate levels (Baker et al., 2003). Furthermore, the sodium-dependent glutamate uptake and the membrane level of the primary glial glutamate transporter (GLT1) were recently reported to be reduced in the nucleus accumbens upon withdrawal from self-administered cocaine (Scofield and Kalivas, 2014). It is important to note that Narita et al. (2006) have indicated that astrocyte-, but not microglia-, related soluble factors were able to amplify both methamphetamineand morphine-dependent rewarding effects. Astrocytic control of glutamatergic signaling during abstinent periods may also critically impact reinstatement of drug-seeking behaviors (Turner et al., 2013). These conclusions stem from studies in which a glia-selective dominantnegative SNARE protein was expressed in mice and subsequently used to assess the contribution of glial transmission on cocaine-induced behaviors. The authors were able to demonstrate that glial transmission is necessary for reinstatement of drug-seeking behaviors triggered by cocaine or associated cues (Turner et al., 2013).

Although much remains to be done to clarify the role of astrocytes in druginduced behaviors, some of their behavioral effects might be consequences to their production of trophic factors that can impact adult neurogenesis (Barkho et al., 2006). This idea is supported by the evidence that exposure to drugs of abuse can influence neurogenesis (Mandyam and Koob, 2012). It is important to also note that gliogenesis in the $\mathrm{mPFC}$ is altered after self-administration of various drugs of abuse (Mandyam and Koob, 2012). Taken together, the impact of drugs of abuse on both neurogenesis and gliogenesis might create an environment that is permissive to the generation and persistence of long-term memories associated with the addictive process.

It is also important to note that the glial-derived neurotrophic factor (GDNF) has also been studied in animal models of addiction (Yan et al., 2007, 2013; Lu et al., 2009). This factor provides trophic support to dopamine neurons and modulates midbrain microglial activation (Rocha et al., 2012). GDNF-dependent neuroadaptations in midbrain VTA neurons appear to play an important role in the development of incubation of cocaine craving ( $\mathrm{Lu}$ et al., 2009). GDNF expression may be also associated with enduring vulnerability to reinstatement of METH-seeking behavior (Yan et al., 2007, 2013). More studies need to be conducted to elucidate how GDNF might influence dopaminergic functions in other brain regions after chronic exposure to psychostimulants and other drugs of abuse.

\section{Oligodendroglia}

Oligodendrocytes are cell types responsible for providing myelin for rapid propagation of action potentials (Nave, 2010). The brain contains an abundant class of progenitor cells that express the chondroitin sulfate proteoglycan, NG2, and the alpha receptor for platelet-derived growth factor (PDGF $\alpha \mathrm{R})$ (Nishiyama, 2007). These $\mathrm{NG} 2^{+}$glial cells are called oligodendrocyte precursor cells (OPCs) because they generate oligodendrocytes during early postnatal development (Nishiyama, 2007). OPCs remain abundant in the adult CNS and retain the ability to differentiate into oligodendrocytes (Kang et al., 2010). They can regenerate oligodendrocytes after their degeneration through chemicalor autoimmune-mediated demyelination (Franklin and Ffrench-Constant, 2008). Oligodendrocytes can also regulate axonal function via their influence on neuron-glial interactions (Fields, 2014)

At present, there is very little information available on the potential effects of drugs of abuse on oligodendrocytes. For example, Lin et al. (2013) used a 3.0Tesla MR scanner to study the brains of 34 heavy smokers and compared them to those of 34 age- and sex-matched controls. They found that heavy smokers had lower fractional anisotropy in the left anterior corpus callosum, an area that corresponded to the genu and rostral body of the corpus callosumm. These smokers did not show any area of increased anisotropy. They reported further that these smokers showed decreased axial diffusivity and increased radial diffusivity, but no changes in mean diffusivity. The authors suggested that their observations might the results of axonal loss and disrupted myelin integrity (Fields, 2014). Importantly, regression analysis revealed that these changes were related to the duration of smoking, thus suggesting that longterm exposure to nicotine and/or other factors in smoke might damage or impair the functions of oligodendrocytes. These observations are consistent with previous observations in chronic cigarette smokers (Paul et al., 2008). It is also important to mention that nicotine can cause significant increases in myelin genes in the prefrontal cortex, caudate putamen, and the nucleus accumbens of rats exposed to the drug in utero (Cao et al., 2013). The impact of these changes on neuronal functions will need to be investigated further.

Animal studies have also revealed certain white matter abnormalities after extended cocaine use. For example, George et al. (2008) investigated memory functions in rats that had 6-h access preday to cocaine. These rats escalated their intake of cocaine and exhibited working memory deficits. In addition, there was a significant correlation between decreased NG2-positive cells and cognitive impairments in these rats. Other investigators have also reported that chronic cocaine can cause decreased level of white matter proteins in the mouse nucleus accumbens (Kovalevich et al., 2012). Opioids also appear to affect the functions of oligodendrocytes. Specifically, perinatal exposure to buprenorphine has been shown to influence brain myelination, in that some doses of the buprenorphine were associated with reduced nuber of myelinatied axons (Sanchez et al., 2008). Buprenorphine also caused an inverted U-type increases in myelin basic proteins (MBPs), with the highest doses causing normalization of the levels of MBPs (Eschenroeder et al., 2012). Low doses of bupenorphine also increeased morphological complexity and increased the percentage of pre-oligodendrocytes that reach maturity. These differentiating effects appear 
to be mediated by stimulation of muopioid receptors (Eschenroeder et al., 2012). In contrast, higher does of the drug might exert their influence through the nociceptin/orphanin FQ (NOP) receptor (Eschenroeder et al., 2012). These observations suggest that further evaluation of oligodendryte functions in adults being treated with opioid agents are necessary.

These animal studies are consistent with the suggestion that myelin dysfunction might account for some of the deficits in white matter integrity described in studies of humans addicted to various substances (Cadet et al., 2014a). More studies are needed to elucidate if electrophysiological abnormalities observed in some models of addiction might be secondary to drug-induced myelin dysfunction and associated abnormalities in conduction of action potentials to synaptic areas.

\section{Microglia}

Microglial cells are the immune cells that reside in the brain parenchyma (Sierra et al., 2014). They are exceptional sensors of their microenvironment and respond by undergoing remarkable changes in morphology and gene expression (Aguzzi et al., 2013). During pathological insults, activated microglial cells thicken and retract their processes, extend filopodia, proliferate and migrate. They also release factors and compounds that can influence neuronal survival. These factors include proinflammatory cytokines, trophic factors, and ROS. They also phagocytose pathogens, degenerating cells, and debris (Schafer et al., 2013). Of relatedness to our present discussion, reactive microgliosis has been detected in several regions of the brains of methamphetamine addicts who had been abstinent for several years (Sekine et al., 2008). These results had suggested that methamphetamine exposure had engendered a process that had enduring effects on the proliferation of reactive microglial cells. These studies in humans found parallelism in preclinical studies documenting that methamphetamine induces microglial activation in the brain (Thomas et al., 2004; Raineri et al., 2012). Along with microglial activation, methamphetamine can increase striatal mRNA expression levels of IL-6 family pro-inflammatory cytokines, leukemia inhibitory factor, oncostatin $\mathrm{m}$, and IL-6 (Robson et al., 2013). These observations are consistent with the idea that the drug might cause neuronal dysfunction via microglia-secreted pro-inflammatory and toxic factors.

In addition to their toxic effects, microglia can alter neuronal excitability by affecting both inhibitory and excitatory synaptic transmission (Sierra et al., 2014). Tremblay et al. (2010) showed that microglia normally contact spines, synaptic terminals, and synaptic clefts in the cortex (Tremblay et al., 2010). Microglia can also regulate basal glutamatergic and GABAergic synaptic transmission in the context of brain injury by a mechanism that involves the increased production of ATP that stimulates the release of brainderived neurotrophic factor (BDNF) from microglial cells (Tsuda et al., 2003; Davalos et al., 2005). BDNF is a neurotrophin that regulates neuronal survival and differentiation. BDNF also modulates neuronal activity and synaptic plasticity (Santos et al., 2010). Because neurons and microglia express BDNF (Trang et al., 2011), this protein may influence a vast array of functions in the brain. Of specific relationship to our discussion, it has been shown that infusion of BDNF into subcortical structures such as the nucleus accumbens and ventral tegmental area enhances cocaine-induced behavioral sensitization and cocaine seeking (Lu et al., 2004; Graham et al., 2007). In contrast, BDNF infusion into the dorsomedial prefrontal cortex following cocaine self-administration attenuates relapse to cocaine seeking after abstinence; cueand cocaine prime-induced reinstatement of cocaine-seeking were similarly affected (Whitfield et al., 2011). Some of the effects of cocaine on BDNF appear to be mediated via induced expression of microRNA 212 (Hollander et al., 2010), with the magnitude of BDNF expression being dependent on a homeostatic interaction of microRNA 212 and MeCP2 in the dorsal striatum (Im et al., 2010). Methamphetamine self-administration also causes increased BDNF expression at both mRNA and protein levels (Cadet et al., 2014b). However, since these studies did not clarify the principal sources of BDNF expression, it remains to be determined the extent to which microglial cells might be influencing these drug-induced changes in BDNF expression.

\section{CONCLUSIONS}

Addiction of licit and illicit substances can be viewed as maladaptive plastic responses to exposure to agents that impact the expression of various genes and proteins in the brain. Some of these proteins are known to be involved in developmental processes that are dormant during adulthood (Cadet, 2009; Cadet et al., 2014b). Drug-induced elevated expression of some of these proteins could have induced glial proliferation, neuronal dedifferentiation, as well as structural and dysfunctional interactions between glial and neuronal cells (Cadet, 2009). Because glial cells are such an integral part of global neuronal function, it will be very important to develop tool sets that can differentiate the short-term impact of drug-induced dysfunctions of glial cells that might negatively impact long-term brain functions. This is important in view of the fact that many neurodegenerative disorders including Parkinson's disease are thought to be secondary to glia-dependent neuroinflammatory responses (Rogers et al., 2007; Tansey and Goldberg, 2010). These statements implicate a need for novel approaches to the treatment of human addicts that emphasize the development of protective agents that could cause a return of their brains toward baseline homeostasis.

\section{ACKNOWLEDGMENTS}

The Intramural Research Program of the National Institute on Drug Abuse (NIDA), $\mathrm{NIH}$, and DHHS supports this paper. Veronica Bisagno is supported by grants PIP11420100100072 and PICT 2012-0924, Argentina.

\section{REFERENCES}

Aguzzi, A., Barres, B. A., and Bennett, M. L. (2013). Microglia: scapegoat, saboteur, or something else? Science 339, 156-161. doi: 10.1126/science. 1227901

Araque, A., Carmignoto, G., Haydon, P. G., Oliet, S. H., Robitaille, R., and Volterra, A. (2014). Gliotransmitters travel in time and space. Neuron 81, 728-739. doi: 10.1016/j.neuron.2014.02.007

Baker, D. A., McFarland, K., Lake, R. W., Shen, H., Tang, X. C., Toda, S., et al. (2003) Neuroadaptations in cystine-glutamate exchange underlie cocaine relapse. Nat. Neurosci. 6, 743-749. doi: $10.1038 / \mathrm{nn} 1069$ 
Barkho, B. Z., Song, H., Aimone, J. B., Smrt, R. D., Kuwabara, T., Nakashima, K., et al. (2006). Identification of astrocyte-expressed factors that modulate neural stem/progenitor cell differentiation. Stem Cells Dev. 15, 407-421. doi: 10.1089/scd.2006.15.407

Cadet, J. L. (2009). Amphetamine recapitulates developmental programs in the zebrafish. Genome Biol. 10:231. doi: 10.1186/gb-2009-10-7-231

Cadet, J. L., Bisagno, V., and Milroy, C. M. (2014a). Neuropathology of substance use disorders. Acta Neuropathol. 127, 91-107. doi: 10.1007/s00401013-1221-7

Cadet, J. L., and Brannock, C. (1998). Free radicals and the pathobiology of brain dopamine systems. Neurochem. Int. 32, 117-131.

Cadet, J. L., Brannock, C., Jayanthi, S., and Krasnova, I. N. (2014b). Transcriptional and epigenetic substrates of methamphetamine addiction and withdrawal: evidence from a long-access selfadministration model in the rat. Mol. Neurobiol. doi: 10.1007/s12035-014-8776-8. [Epub ahead of print].

Cao, J., Dwyer, J. B., Gautier, N. M., Leslie, F. M., and Li, M. D. (2013). Central myelin gene expression during postnatal development in rats exposed to nicotine gestationally. Neurosci. Lett. 553, 115-120. doi: 10.1016/j.neulet.2013.08.012

Cotrina, M. L., Lin, J. H., López-García, J. C., Naus, C. C., and Nedergaard, M. (2000). ATP-mediated glia signaling. J. Neurosci. 20, 2835-2844.

D’Ascenzo, M., Fellin, T., Terunuma, M., RevillaSanchez, R., Meaney, D. F., Auberson, Y. P., et al. (2007). mGluR5 stimulates gliotransmission in the nucleus accumbens. Proc. Natl. Acad. Sci. U.S.A. 104, 1995-2000. doi: 10.1073/pnas.0609408104

Davalos, D., Grutzendler, J., Yang, G., Kim, J. V., Zuo, Y., Jung, S., et al. (2005). ATP mediates rapid microglial response to local brain injury in vivo. Nat. Neurosci. 8, 752-758. doi: 10.1038/ nn 1472

Dietrich, J. B., Mangeol, A., Revel, M. O., Burgun, C., Aunis, D., and Zwiller, J. (2005). Acute or repeated cocaine administration generates reactive oxygen species and induces antioxidant enzyme activity in dopaminergic rat brain structures. Neuropharmacology 48, 965-974. doi: 10.1016/j.neuropharm.2005.01.018

Eschenroeder, A. C., Vestal-Laborde, A. A., Sanchez, E. S., Robinson, S. E., and Sato-Bigbee, C. (2012). Oligodendrocyte responses to buprenorphine uncover novel and opposing roles of $\mu$ opioid- and nociceptin/orphanin FQ receptors in cell development: implications for drug addiction treatment during pregnancy. Glia 60, 125-136. doi: 10.1002/glia.21253

Fields, R. D. (2014). Neuroscience. Myelin-more than insulation. Science 344, 264-266. doi: 10.1126/science. 1253851

Franklin, R. J., and Ffrench-Constant, C. (2008). Remyelination in the CNS: from biology to therapy. Nat. Rev. Neurosci. 9, 839-855. doi: $10.1038 / \mathrm{nrn} 2480$

George, O., Mandyam, C. D., Wee, S., and Koob, G. F. (2008). Extended access to cocaine selfadministration produces long-lasting prefrontal cortex-dependent working memory impairments. Neuropsychopharmacology 33, 2474-2482. doi: 10.1038/sj.npp.1301626
Glass, C. K., Saijo, K., Winner, B., Marchetto, M. C., and Gage, F. H. (2010). Mechanisms underlying inflammation in neurodegeneration. Cell 140, 918-934. doi: 10.1016/j.cell.2010.02.016

Graham, D. L., Edwards, S., Bachtell, R. K., DiLeone, R. J., Rios, M., and Self, D. W. (2007). Dynamic BDNF activity in nucleus accumbens with cocaine use increases self-administration and relapse. Nat. Neurosci. 10, 1029-1037. doi: 10.1038/nn1929

Haydon, P. G., Blendy, J., Moss, S. J., and Rob Jackson, F. (2009). Astrocytic control of synaptic transmission and plasticity: a target for drugs of abuse? Neuropharmacology 56(Suppl. 1), 83-90. doi: 10.1016/j.neuropharm.2008.06.050

Hollander, J. A., Im, H. I., Amelio, A. L., Kocerha, J., Bali, P., Lu, Q., et al. (2010). Striatal microRNA controls cocaine intake through CREB signalling. Nature 466, 197-202. doi: 10.1038/nature09202

Im, H. I., Hollander, J. A., Bali, P., and Kenny, P. J. (2010). MeCP2 controls BDNF expression and cocaine intake through homeostatic interactions with microRNA-212. Nat. Neurosci. 13, 1120-1127. doi: 10.1038/nn.2615

Jeong, H. K., Ji, K., Min, K., and Joe, E. H. (2013). Brain inflammation and microglia: facts and misconceptions. Exp. Neurobiol. 22, 59-67. doi: 10.5607/en.2013.22.2.59

Jourdain, P., Bergersen, L. H., Bhaukaurally, K., Bezzi, P., Santello, M., Domercq, M., et al. (2007). Glutamate exocytosis from astrocytes controls synaptic strength. Nat. Neurosci. 10, 331-339. doi: 10.1038/nn1849

Kang, S. H., Fukaya, M., Yang, J. K., Rothstein, J. D., and Bergles, D. E. (2010). NG2+ CNS glial progenitors remain committed to the oligodendrocyte lineage in postnatal life and following neurodegeneration. Neuron 68, 668-681. doi: 10.1016/j.neuron.2010.09.009

Koob, G. F., and Volkow, N. D. (2010). Neurocircuitry of addiction. Neuropsychopharmacology 35, 217-238. doi: 10.1038/npp.2009.110

Kovalevich, J., Corley, G., Yen, W., Rawls, S. M., and Langford, D. (2012). Cocaine-induced loss of white matter proteins in the adult mouse nucleus accumbens is attenuated by administration of a $\beta$-lactam antibiotic during cocaine withdrawal. Am. J. Pathol. 181, 1921-1927. doi: 10.1016/j.ajpath.2012.08.013

Krasnova, I. N., and Cadet, J. L. (2009). Methamphetamine toxicity and messengers of death. Brain Res. Rev. 60, 379-407. doi: 10.1016/j.brainresrev.2009.03.002

Lin, F., Wu, G., Zhu, L., and Lei, H. (2013). Heavy smokers show abnormal microstructural integrity in the anterior corpus callosum: a diffusion tensor imaging study with tract-based spatial statistics. Drug Alcohol Depend. 129, 82-87. doi: 10.1016/j.drugalcdep.2012.09.013

Lu, L., Dempsey, J., Liu, S. Y., Bossert, J. M., and Shaham, Y. (2004). A single infusion of brain-derived neurotrophic factor into the ventral tegmental area induces long-lasting potentiation of cocaine seeking after withdrawal. J. Neurosci. 24, 1604-1611. doi: 10.1523/JNEUROSCI.512403.2004

Lu, L., Wang, X., Wu, P., Xu, C., Zhao, M., Morales, M., et al. (2009). Role of ventral tegmental area glial cell line-derived neurotrophic factor in incubation of cocaine craving. Biol. Psychiatry
66, 137-145. doi: 10.1016/j.biopsych.2009. 02.009

Mandyam, C. D., and Koob, G. F. (2012). The addicted brain craves new neurons: putative role for adult-born progenitors in promoting recovery. Trends Neurosci. 35, 250-260. doi: 10.1016/j.tins.2011.12.005

Moran, M. M., McFarland, K., Melendez, R. I., Kalivas, P. W., and Seamans, J. K. (2005). Cystine/glutamate exchange regulates metabotropic glutamate receptor presynaptic inhibition of excitatory transmission and vulnerability to cocaine seeking. J. Neurosci. 25, 6389-6393. doi: 10.1523/JNEUROSCI.1007-05.2005

Mothet, J. P., Pollegioni, L., Ouanounou, G., Martineau, M., Fossier, P., and Baux, G. (2005). Glutamate receptor activation triggers a calciumdependent and SNARE protein-dependent release of the gliotransmitter D-serine. Proc. Natl. Acad. Sci. U.S.A. 102, 5606-5611. doi: 10.1073/pnas.0408483102

Narita, M., Miyatake, M., Narita, M., Shibasaki, M., Shindo, K., Nakamura, A., et al. (2006). Direct evidence of astrocytic modulation in the development of rewarding effects induced by drugs of abuse. Neuropsychopharmacology 31, 2476-2488. doi: 10.1038/sj.npp.1301007

Nave, K. A. (2010). Myelination and support of axonal integrity by glia. Nature 468, 244-252. doi: 10.1038/nature09614

Nishiyama, A. (2007). Polydendrocytes: NG2 cells with many roles in development and repair of the CNS. Neuroscientist 13, 62-76. doi: $10.1177 / 1073858406295586$

O'Shea, E., Urrutia, A., Green, A. R., and Colado, M. I. (2014). Current preclinical studies on neuroinflammation and changes in bloodbrain barrier integrity by MDMA and methamphetamine. Neuropharmacology. doi: 10.1016/j.neuropharm.2014.02.015. [Epub ahead of print].

Paul, R. H., Grieve, S. M., Niaura, R., David, S. P., Laidlaw, D. H., Cohen, R., et al. (2008). Chronic cigarette smoking and the microstructural integrity of white matter in healthy adults: a diffusion tensor imaging study. Nicotine Tob. Res. 10, 137-147. doi: 10.1080/14622200701767829

Pow, D. V. (2001). Visualising the activity of the cystine-glutamate antiporter in glial cells using antibodies to aminoadipic acid, a selectively transported substrate. Glia 34, 27-38. doi: 10.1002/glia.1037

Raineri, M., Gonzalez, B., Goitia, B., Garcia-Rill, E., Krasnova, I. N., Cadet, J. L., et al. (2012). Modafinil abrogates methamphetamine-induced neuroinflammation and apoptotic effects in the mouse striatum. PLoS ONE 7:e46599. doi: 10.1371/journal.pone.0046599

Robson, M. J., Turner, R. C., Naser, Z. J., McCurdy, C. R., Huber, J. D., and Matsumoto, R. R. (2013). SN79, a sigma receptor ligand, blocks methamphetamine-induced microglial activation and cytokine upregulation. Exp. Neurol. 247, 134-142. doi: 10.1016/j.expneurol.2013.04.009

Rocha, S. M., Cristovão, A. C., Campos, F. L., Fonseca, C. P., and Baltazar, G. (2012). Astrocytederived GDNF is a potent inhibitor of microglial activation. Neurobiol. Dis. 47, 407-415. doi: 10.1016/j.nbd.2012.04.014 
Rogers, J., Mastroeni, D., Leonard, B., Joyce, J., and Grover, A. (2007). Neuroinflammation in Alzheimer's disease and Parkinson's disease: are microglia pathogenic in either disorder? Int. Rev. Neurobiol. 82, 235-246. doi: 10.1016/S00747742(07)82012-5

Sanchez, E. S., Bigbee, J. W., Fobbs, W., Robinson, S. E., and Sato-Bigbee, C. (2008). Opioid addiction and pregnancy: perinatal exposure to buprenorphine affects myelination in the developing brain. Glia 56, 1017-1027. doi: 10.1002/glia.20675

Santos, A. R., Comprido, D., and Duarte, C. B. (2010). Regulation of local translation at the synapse by BDNF.Prog. Neurobiol. 92, 505-516. doi: 10.1016/j.pneurobio.2010.08.004

Schafer, D. P., Lehrman, E. K., and Stevens, B. (2013). The "quad-partite" synapse: microgliasynapse interactions in the developing and mature CNS. Glia 61, 24-36. doi: 10.1002/glia.22389

Scofield, M. D., and Kalivas, P. W. (2014). Astrocytic dysfunction and addiction: consequences of impaired glutamate homeostasis. Neuroscientist. doi: 10.1177/1073858413520347. [Epub ahead of print].

Sekine, Y., Ouchi, Y., Sugihara, G., Takei, N., Yoshikawa, E., Nakamura, K., et al. (2008). Methamphetamine causes microglial activation in the brains of human abusers. J. Neurosci. 28, 5756-5761. doi: 10.1523/JNEUROSCI.117908.2008

Shiba, T., Yamato, M., Kudo, W., Watanabe, T., Utsumi, H., and Yamada, K. (2011). In vivo imaging of mitochondrial function in methamphetamine-treated rats. Neuroimage 57, 866-872. doi: 10.1016/j.neuroimage.2011.05.041

Sierra, A., Beccari, S., Diaz-Aparicio, I., Encinas, J. M., Comeau, S., and Tremblay, M. È. (2014). Surveillance, phagocytosis, and inflammation: how never-resting microglia influence adult hippocampal neurogenesis. Neural Plast. 2014:610343. doi: 10.1155/2014/610343

Tansey, M. G., and Goldberg, M. S. (2010). Neuroinflammation in Parkinson's disease: its role in neuronal death and implications for therapeutic intervention. Neurobiol. Dis. 37, 510-518. doi: 10.1016/j.nbd.2009.11.004
Thomas, D. M., Walker, P. D., Benjamins, J. A., Geddes, T. J., and Kuhn, D. M. (2004). Methamphetamine neurotoxicity in dopamine nerve endings of the striatum is associated with microglial activation. J. Pharmacol. Exp. Ther. 311, 1-7. doi: 10.1124/jpet.104.070961

Trang, T., Beggs, S., and Salter, M. W. (2011). Brain-derived neurotrophic factor from microglia: a molecular substrate for neuropathic pain. Neuron Glia Biol. 7, 99-108. doi: 10.1017/S1740925X12000087

Tremblay, M. Ė., Lowery, R. L., and Majewska, A. K. (2010). Microglial interactions with synapses are modulated by visual experience. PLoS Biol. 8:e1000527. doi: 10.1371/journal.pbio.1000527

Tsuda, M., Shigemoto-Mogami, Y., Koizumi, S., Mizokoshi, A., Kohsaka, S., Salter, M., et al. (2003). $\mathrm{P} 2 \mathrm{X} 4$ receptors induced in spinal microglia gate tactile allodynia after nerve injury. Nature 424, 78-783. doi: 10.1038/nature01786

Turner, J. R., Ecke, L. E., Briand, L. A., Haydon, P. G., and Blendy, J. A. (2013). Cocaine-related behaviors in mice with deficient gliotransmission. Psychopharmacology (Berl) 226, 167-176. doi: 10.1007/s00213-012-2897-4

Van Wagoner, N. J., Oh, J. W., Repovic, P., and Benveniste, E. N. (1999). Interleukin-6 (IL-6) production by astrocytes: autocrine regulation by IL6 and the soluble IL-6 receptor. J. Neurosci. 19, 5236-5244.

Volkow, N. D., Wang, G.-J., Fowler, J. S., and Tomasi, D. (2012). Addiction circuitry in the human brain. Annu. Rev. Pharmacol. Toxicol. 52, 321-336. doi: 10.1146/annurev-pharmtox-010611-134625

Volterra, A., and Meldolesi, J. (2005). Astrocytes, from brain glue to communication elements: the revolution continues. Nat. Rev. Neurosci. 6, 626-640. doi: $10.1038 /$ nrn 1722

Wake, H., Moorhouse, A. J., Miyamoto, A., and Nabekura, J. (2013). Microglia: actively surveying and shaping neuronal circuit structure and function. Trends Neurosci. 36, 209-217. doi: 10.1016/j.tins.2012.11.007

Whitfield, T. W. Jr., Shi, X., Sun, W. L., and McGinty, J. F. (2011). The suppressive effect of an intra-prefrontal cortical infusion of BDNF on cocaine-seeking is Trk receptor and extracellular signal-regulated protein kinase mitogen-activated protein kinase dependent. J. Neurosci. 31, 834-842. doi: 10.1523/JNEUROSCI.4986-10.2011

Wigley, R., Hamilton, N., Nishiyama, A., Kirchhoff, F., and Butt, A. M. (2007). Morphological and physiological interactions of NG2-glia with astrocytes and neurons. J. Anat. 210, 661-670. doi 10.1111/j.1469-7580.2007.00729.x

Yan, Y., Miyamoto, Y., Nitta, A., Muramatsu, S., Ozawa, K., Yamada, K., et al. (2013). Intrastriatal gene delivery of GDNF persistently attenuates methamphetamine self-administration and relapse in mice. Int. J. Neuropsychopharmacol. 16, 1559-1567. doi: 10.1017/S146114571 2001575

Yan, Y., Yamada, K., Niwa, M., Nagai, T., Nitta, A., and Nabeshima, T. (2007). Enduring vulnerability to reinstatement of methamphetamine-seeking behavior in glial-cell-line-derived neurotrophic factor mutant mice. FASEB J. 2, 1994-2004. doi: 10.1096/fj.06-7772com

Conflict of Interest Statement: The authors declare that the research was conducted in the absence of any commercial or financial relationships that could be construed as a potential conflict of interest.

Received: 25 July 2014; accepted: 15 August 2014; published online: 02 September 2014.

Citation: Cadet JL and Bisagno V (2014) Glial-neuronal ensembles: partners in drug addiction-associated synaptic plasticity. Front. Pharmacol. 5:204. doi: 10.3389/ fphar.2014.00204

This article was submitted to Neuropharmacology, a section of the journal Frontiers in Pharmacology.

Copyright (C) 2014 Cadet and Bisagno. This is an open-access article distributed under the terms of the Creative Commons Attribution License (CC BY). The use, distribution or reproduction in other forums is permitted, provided the original author(s) or licensor are credited and that the original publication in this journal is cited, in accordance with accepted academic practice. No use, distribution or reproduction is permitted which does not comply with these terms. 